\title{
Quantitative assessment of symptomatic intracranial atherosclerosis and lenticulostriate arteries in recent stroke patients using whole-brain high-resolution cardiovascular magnetic resonance imaging
}

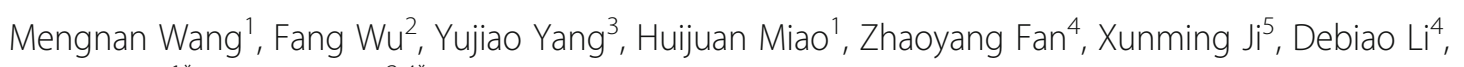
Xiuhai Guo ${ }^{1 *}$ and Qi Yang ${ }^{2,4^{*}}$

\begin{abstract}
Background: It has been shown that intracranial atherosclerotic stenosis (ICAS) has heterogeneous features in terms of plaque instability and vascular remodeling. Therefore, quantitative information on the changes of intracranial atherosclerosis and lenticulostriate arteries (LSAs) may potentially improve understanding of the pathophysiological mechanisms underlying stroke and may guide the treatment and work-up strategies. Our present study aimed to use a novel whole-brain high-resolution cardiovascular magnetic resonance imaging (WB-HRCMR) to assess both ICAS plaques and LSAs in recent stroke patients.

Methods: Twenty-nine symptomatic and 23 asymptomatic ICAS patients were enrolled in this study from Jan 2015 through Sep 2017 and all patients underwent WB-HRCMR. Intracranial atherosclerotic plaque burden, plaque enhancement volume, plaque enhancement index, as well as the number and length of LSAs were evaluated in two groups. Enhancement index was calculated as follows: ([Signal intensity $(\mathrm{SI})_{\text {plaque }} / \mathrm{S} \mathrm{I}_{\text {normal }}$ wall on post-contrast imaging] - [SI plaque $/ S I_{\text {normal wall }}$ on matched pre-contrast imaging])/(SI plaque / SI normal wall on matched pre-contrast imaging). Logistic regression analysis was used to investigate the independent high risk plaque and LSAs features associated with stroke.

Results: Symptomatic ICAS patients exhibited larger enhancement plaque volume $\left(20.70 \pm 3.07 \mathrm{~mm}^{3}\right.$ vs. $6.71 \pm 1.87 \mathrm{~mm}^{3}$ $P=0.001)$ and higher enhancement index $(0.44 \pm 0.08 \mathrm{vs} .0 .09 \pm 0.06 P=0.001)$ compared with the asymptomatic ICAS. The average length of LSAs in symptomatic ICAS $(20.95 \pm 0.87 \mathrm{~mm})$ was shorter than in asymptomatic ICAS $(24.04 \pm 0$. $95 \mathrm{~mm})(P=0.02)$. Regression analysis showed that the enhancement index $(100.43,95 \% \mathrm{Cl}-4.02-2510.96 ; P=0.005)$ and the average length of $\mathrm{LSAs}(0.80,95 \% \mathrm{Cl}-0.65-0.99 ; P=0.036)$ were independent factors for predicting of stroke.

Conclusion: WB-HRCMR enabled the comprehensive quantitative evaluation of intracranial atherosclerotic lesions and perforating arteries. Symptomatic ICAS had distinct plaque characteristics and shorter LSA length compared with asymptomatic ICAS.
\end{abstract}

Keywords: Intracranial atherosclerotic stenosis, High-resolution cardiovascular magnetic resonance imaging, Stroke, Lenticulostriate arteries

\footnotetext{
* Correspondence: guoxhxuan@126.com; qi.yang@cshs.org;

yangyangqiqi@gmail.com

'Department of Neurology, Xuanwu Hospital, Capital Medical University,

Beijing 100053, China

2Department of Radiology, Xuanwu Hospital, Capital Medical University,

Beijing 100053, China

Full list of author information is available at the end of the article
}

(c) The Author(s). 2018 Open Access This article is distributed under the terms of the Creative Commons Attribution 4.0 International License (http://creativecommons.org/licenses/by/4.0/), which permits unrestricted use, distribution, and reproduction in any medium, provided you give appropriate credit to the original author(s) and the source, provide a link to the Creative Commons license, and indicate if changes were made. The Creative Commons Public Domain Dedication waiver (http://creativecommons.org/publicdomain/zero/1.0/) applies to the data made available in this article, unless otherwise stated. 


\section{Background}

Intracranial atherosclerotic stenosis (ICAS) is one of the most common causes of ischemic stroke, which is associated with high morbidity and mortality rates in Asian countries [1-4]. The initial and follow-up assessment of stroke patients rely mostly upon the evaluation of luminal stenosis via several methods, including transcranial Doppler (TCD), computed tomography angiography (CTA) and magnetic resonance angiography (MRA) [5-8]. Recently, high-resolution cardiovascular magnetic resonance imaging (HR-CMR) has been used to directly depict intracranial vessel wall plaques $[9,10]$. Two-dimensional imaging techniques were commonly used for HR-CMR to assess intracranial atherosclerotic plaque morphology and plaque composition [11-13]. However, limited spatial temporal resolution hampered its application in quantitative measurement of vessel wall dimensions and visualization of lenticulostriate arteries (LSAs). Several studies have demonstrated that flow-sensitive black blood magnetic resonance angiography (FSBB-MRA) based on 3D gradient-echo sequence can be specifically used to visualize LSAs [14-16]. Our recent studies have demonstrated the feasibility of whole-brain high-resolution magnetic resonance imaging (WB-HRCMR), which enables combined evaluation of plaque and LSAs in one image setting $[17,18]$. Thus, in this study, we aimed to use WB-HRCMR to quantitatively investigate different features of plaque and LSAs in symptomatic versus asymptomatic ICAS groups.

\section{Methods}

\section{Study population}

From January 2015 to September 2017, consecutive symptomatic and asymptomatic ICAS patients who were admitted to or visit the Department of Neurology of our hospital were consecutively recruited. The inclusion criteria: (1) age 18-80 years old; (2) symptomatic ICAS referred to first time acute ischemic stroke in the middle cerebral artery (MCA) territory identified by diffusion weighted imaging (DWI) performed within $72 \mathrm{~h}$ of symptom onset, and asymptomatic ICAS referred to patients who were diagnosed with other diseases without history of stroke but had MCA stenosis confirmed on image screening; (3) All enrolled subjects had moderate (stenosis: 50-69\%) or severe (stenosis: 70-99\%) MCA stenosis, confirmed by MRA, CTA, or digital subtraction angiography. The exclusion criteria included: (1) DWI with lacunar infarction: cerebral infarction in LSAs territory involving less than two layers or the diameter of the infarction $<15 \mathrm{~mm}$; (2) coexistent ipsilateral internal carotid stenosis; (3) preexisting conditions such as vasculitis, moyamoya disease, dissection, reversible cerebral vasoconstriction syndrome (RCVS); (4) evidence of cardioembolism (e.g., arterial fibrillation, mechanical prosthetic valve disease, sick sinus syndrome, dilated cardiomyopathy). All patients underwent WB-HRCMR within 2 weeks of symptom onset. Informed consent was obtained from all participants, and all protocols were approved by the Institutional Review Board.

\section{WB-HRCMR}

All patients underwent WB-HRCMR with a 3-Tesla system (Magnetom Verio; Siemens Healthineers, Erlangen, Germany) and a standard 32-channel head coil. WB-HRCMR was performed at both pre-contrast and post-contrast states by using a 3D T1-weighted wholebrain vessel wall CMR technique known as inversion-recovery (IR) prepared SPACE (Sampling Perfection with Application-optimized Contrast using different flip angle Evolutions) [17, 18], with the following parameters: TR/ $\mathrm{TE}=900 / 15 \mathrm{~ms}$; field of view $=170 \times 170 \mathrm{~mm}^{2} ; 240$ slices with slice thickness of $0.53 \mathrm{~mm}$; voxel size = $0.53 \times 0.53 \times 0.53 \mathrm{~mm}^{3} ;$ scan time $=8 \mathrm{~min}$. The CMR contrast agent, gadopentetate dimeglumine (Magnevist; Schering, Berlin, Germany), was injected through an antecubital vein $(0.1 \mathrm{mmol}$ per kilogram of body weight), and WB-HRCMR was repeated $5 \mathrm{~min}$ after injection was performed.

\section{WB-HRCMR image analysis}

Evaluation of WB-HRCMR was conducted in consensus by two experienced neuroradiologists blinded to the patient's clinical details. Commercial software (Vessel Analysis, Oak Medical Imaging Technologies, Inc.) with 3D multi-planar reformation and region-of-interest (ROI) signal measurement functionalities was used for quantitative analysis. A plaque was defined as thickening of the vessel wall using its adjacent proximal, distal, or contralateral vessel segment as a reference. A culprit plaque was defined as (1) the only lesion within the vascular vicinity of the stroke or (2) the most stenotic lesion when multiple plaques were present within the same vascular territory of the stroke. The vessel area (VA) and lumen area were measured by manually tracing vessel and lumen boundaries. The difference between VA and lumen area was the wall area (WA). Stenosis degree was defined as (1-lesion lumen area/reference lumen area) $\times$ $100 \%$. The remodeling index (RI) was calculated as the ratio of the lesion VA to the reference VA. The wall area index was defined as the ratio of the lesion WA to the reference WA. And the plaque burden was calculated as WA/VA $\times 100 \%$. The mean signal intensity (SI) values of culprit plaques and reference vessel wall were measured on pre- and post-contrast WBHRCMR images.

Pre- and post-contrast WB-HRCMR were first co-registered and two-dimensional short-axis images were then 
generated for the measurement of MCA plaque enhancement. Care was taken to ensure that the short-axis views of the plaque were perpendicular to the M1 segment of MCA. Fusion image of pre- and post-contrast WB-HRCMR have been utilized for the segmentation of the enhanced area of plaque and the enhancement volume was then calculated (Fig. 1). Enhancement index

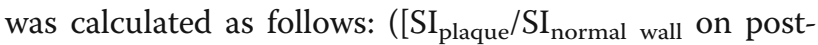
contrast imaging $]-\left[\mathrm{SI}_{\text {plaque }} / \mathrm{SI}_{\text {normal wall }}\right.$ on matched precontrast imaging] $) /\left(\mathrm{SI}_{\text {plaque }} / \mathrm{SI}_{\text {normal wall }}\right.$ on matched precontrast imaging).

LSAs images were generated using five to six slices of minimum intensity projection (MinIP) in coronal direction with 10-15 $\mathrm{mm}$ thickness on pre-contrast WB-HRCMR. LSA branches longer than $5 \mathrm{~mm}$ were traced and analyzed by using these images [14]. When LSA branches less than $5 \mathrm{~mm}$ from the MCA origin, each branch was counted and measured separately, because more than $70 \%$ of branches were found to originate from common trunks [19].

\section{Statistical analysis}

All quantitative data were expressed as means \pm standard deviations. Categorical variables were analyzed using Chi-square test and continuous variables were compared using t-test between the two groups. A logistic regression analysis with the method of enter stepwise was used to look for independent predictors of stroke. A P-value of less than 0.05 indicated statistical significance. All statistical analyzes were performed by using commercial software (SPSS 22.0, International Business Machnines, Armonk, New York, USA).

\section{Results}

\section{Patient characteristics}

One hundred and one patients were consecutively recruited in the study and forty-nine patients were excluded from analysis due to poor image quality $(N=5)$, $<50 \%$ MCA stenosis $(N=4)$, evidence of cardio embolism $(N=7)$, patients with other etiologies $(N=13)$, and patients with lacunar infarction $(N=20)$. The remaining 52 patients were enrolled of which 29 were symptomatic. The demographic data was illustrated in Table 1. No statistically significant differences in patient demographics and the main clinical characteristics were found.

\section{ICAS plaque location}

A total of seventy-nine ICAS plaques were observed. In symptomatic ICAS group, $29(61.7 \%)$ plaques were found in MCA and 18 (38.3\%) were in intracranial ICA. In asymptomatic ICAS group, $23(71.8 \%)$ plaques were detected in MCA, 9 (28.2\%) were in intracranial ICA. No statistically significant differences in MCA plaque distribution were found $(P=0.469)$ between the two groups. All culprit plaques in MCA were included for the final analysis.

\section{ICAS plaque characteristics}

A total of fifty-two MCA plaques were included for the final analysis. The degrees of stenoses, RI, WA, and plaque burden did not differ significantly between two groups. Symptomatic MCA demonstrated greater plaque enhancement, including larger enhancement volume (20.70 $\pm 3.07 \mathrm{~mm}^{3}$ vs. $\left.6.71 \pm 1.87 \mathrm{~mm}^{3}, P=0.001\right)$ and higher enhancement index $(0.44 \pm 0.08$ vs. $0.09 \pm 0.06, P=0.001)$

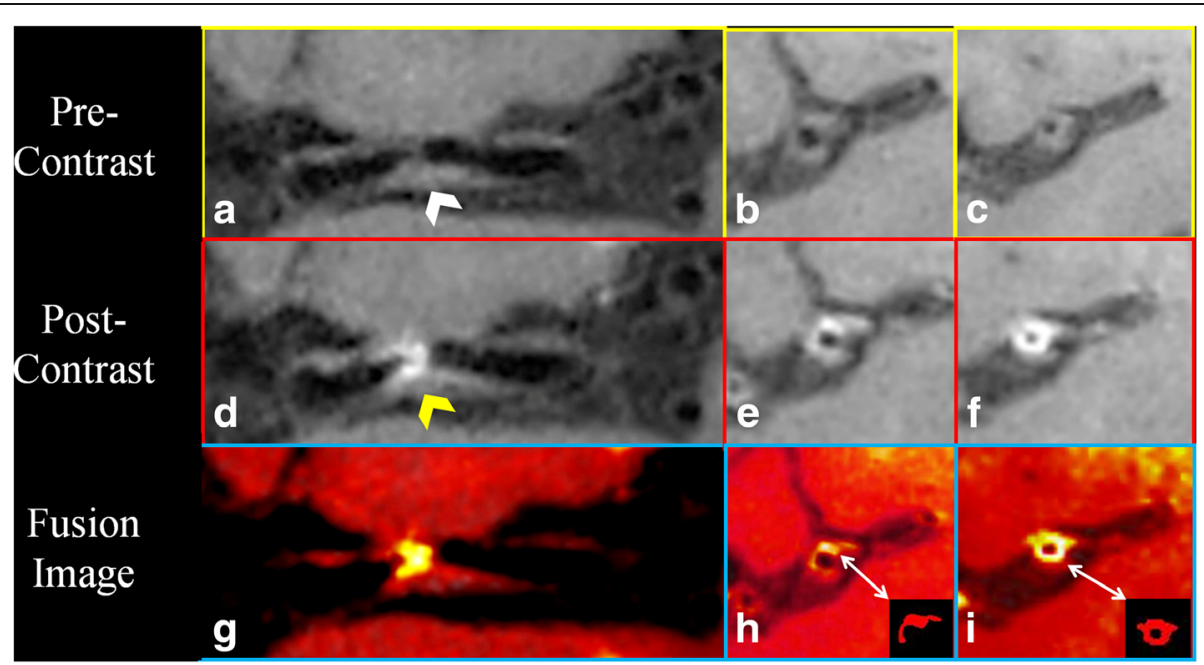

Fig. 1 Pre-contrast coronal and cross-sectional whole brain high resolution cardiovascular magnetic resonance (WB-HRCMR) images showed diffused plaque (a-c, white arrow) located on middle cerebral artery (MCA). Partial enhancement of the plaque was observed (d-f, yellow arrow). The enhancement plaque area was segmented through fusion images $(\mathbf{h}, \mathbf{i})$. The plaque enhanced volume was $11.02 \mathrm{~mm}^{3}$ 
Table 1 Demographic in symptomatic and asymptomatic ICAS patients

\begin{tabular}{|c|c|c|c|}
\hline & Symptomatic ICAS $(N=29)$ & Asymptomatic ICAS $(N=23)$ & $P$ value \\
\hline Age (mean $\pm S D$, years) & $46.00 \pm 2.32$ & $50.30 \pm 2.36$ & 0.397 \\
\hline Male No. (\%) & 20(69) & $13(56.5)$ & 0.632 \\
\hline Body mass index (mean $\left.\pm \mathrm{SD}, \mathrm{kg} / \mathrm{cm}^{2}\right)$ & $24.86 \pm 1.08$ & $24.75 \pm 0.74$ & 0.939 \\
\hline Hypertension No. (\%) & $12(41.4)$ & $11(47.8)$ & 0.780 \\
\hline Diabetes No. (\%) & $4(13.8)$ & $4(17.4)$ & 1 \\
\hline Hyperlipidemia No (\%) & $10(34.5)$ & $9(39.1)$ & 0.778 \\
\hline Smoker No. (\%) & $15(51.7)$ & $11(47.8)$ & 0.477 \\
\hline $\mathrm{LDL}-\mathrm{c}($ mean $\pm \mathrm{SD}, \mathrm{mmol} / \mathrm{L})$ & $2.23 \pm 0.14$ & $2.32 \pm 0.15$ & 0.274 \\
\hline $\mathrm{HDL}-\mathrm{c}($ mean $\pm \mathrm{SD}, \mathrm{mmol} / \mathrm{L})$ & $1.04 \pm 0.05$ & $1.08 \pm 0.08$ & 0.203 \\
\hline Triglycerides (mean $\pm \mathrm{SD}, \mathrm{mmol} / \mathrm{L}$ ) & $1.45 \pm 0.12$ & $1.43 \pm 0.17$ & 0.380 \\
\hline Total cholesterol (mean $\pm \mathrm{SD}, \mathrm{mmol} / \mathrm{L}$ ) & $3.80 \pm 0.17$ & $3.67 \pm 0.22$ & 0.451 \\
\hline
\end{tabular}

LDL-c Low Density Lipoprotein-cholesterol, HDL-c High Density Lipoprotein-cholesterol

(Fig. 2). Two representative cases of symptomatic and asymptomatic MCA are presented in Figs. 3 and 4.

\section{The LSAs features}

In order to compare the several features of LSAs, twenty age-and sex-matched healthy subjects were included as normal controls. The mean number of LSAs was $3.65 \pm$ 0.18 in symptomatic group, $3.87 \pm 0.21$ in asymptomatic group and $4.55 \pm 0.19$ on normal controls, respectively. There was significant difference between symptomatic group and normal controls $(P=0.002)$, and asymptomatic group also had statistical differences in LSAs branches compared with normal controls $(P=0.020)$. Symptomatic group had significant shorter total length of LSAs than normal controls $(P<0.001)$ but no difference was found between asymptomatic and normal

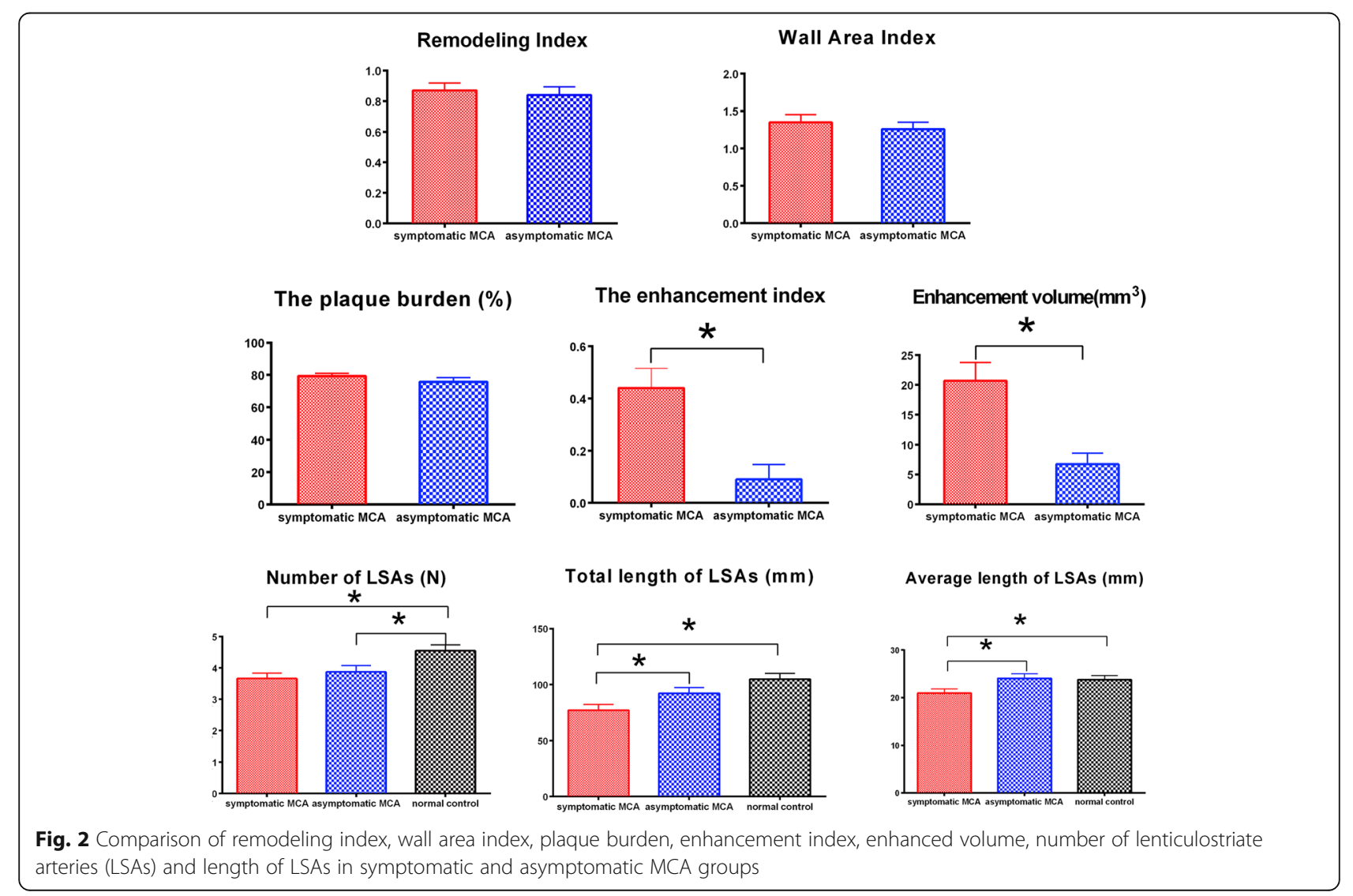




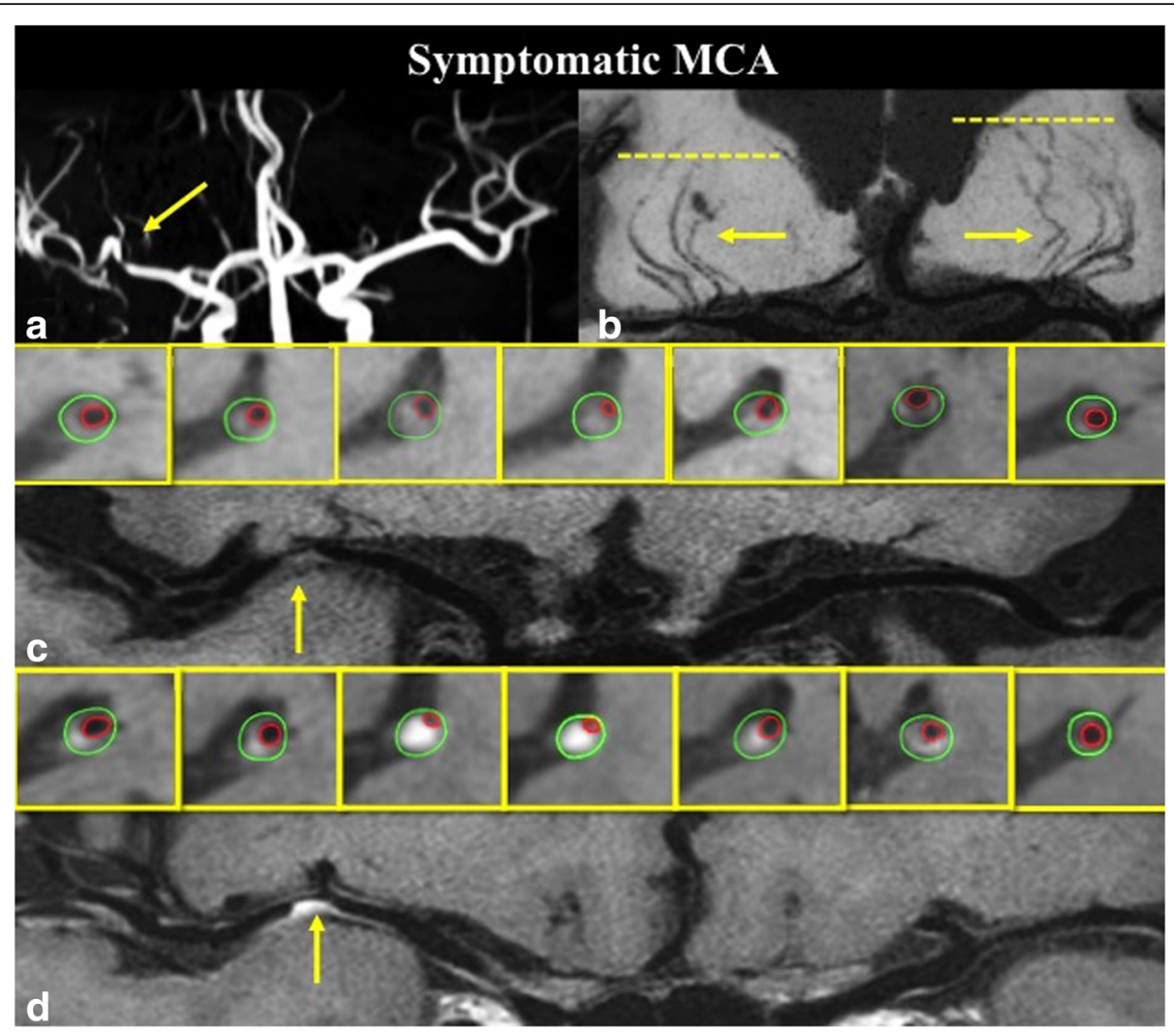

Fig. 3 A 61 years old symptomatic ICAS patient with severe stenosis on right MCA (a), coronal MinIP revealed the decrease of right LSA branches compared to the left side (b); pre-contrast curved WB-HRCMR and cross-sectional images showed a plaque (c, arrow) on the MCA wall; Post-contrast WB-HRCMR showed extensive enhanced plaque volume which can be measured on corresponding cross-sectional images

groups $(P=0.111)$. The symptomatic group had shorter average length than both the asymptomatic groups $(P=$ $0.02)$ and the normal controls $(P=0.034)$. Table 2 summarizes detailed characteristics of the two groups.

\section{Multivariate analysis}

In a logistic regression analysis, the higher enhancement index and shorter average length of LSAs were independently associated with stroke. Odds ratios for enhancement index and average length of LSAs were 100.43 and 0.80 (95\% confidence interval 4.02-2510.96 and $0.65-0.99 ; P=0.005$ and 0.036 ) respectively.

\section{Discussion}

In this study, we found that symptomatic MCA plaques exhibited a higher enhancement index and larger enhancement volume than the asymptomatic group. Furthermore, a significant reduction in the average number and length of LSAs in symptomatic ICAS groups was also found. To the best of our knowledge, this is the first study using WB-HRCMR to quantitatively explore the intracranial high risk plaque characteristics and LSA features in one imaging setting in ICAS patients.
Although variable refocusing flip angle sequences have been the most extensively studied 3D techniques for intracranial vessel wall imaging to date, it is still associated with inadequate suppression of cerebrospinal fluid (CSF) signals and limited field of view. Some lesions may be missed, especially in the more distally vessels. This may cause an underestimation of the true intracranial plaque burden. WB-HRCMR technique allows for whole brain coverage, relatively high and isotropic spatial resolution, and more importantly, remarkable suppression of CSF and enhanced T1 contrast weighting. It enables the measurement of total intracranial plaque burden, plaque morphology and perforating arteries together.

Previous studies found that enhancement of an intracranial atherosclerotic plaque is associated with a recent ischemic event, and is independent of plaque thickness [20-24]. However, in most studies, the extent of plaque enhancement was not quantitatively measured [21, 24-26] and qualitative methods have been used to categorize the degree of plaque enhancement by comparing the enhancement of plaque and the pituitary on MR [25]. Our findings are in line with the these studies, however, with a step forward quantitative method. We registered and fused the 


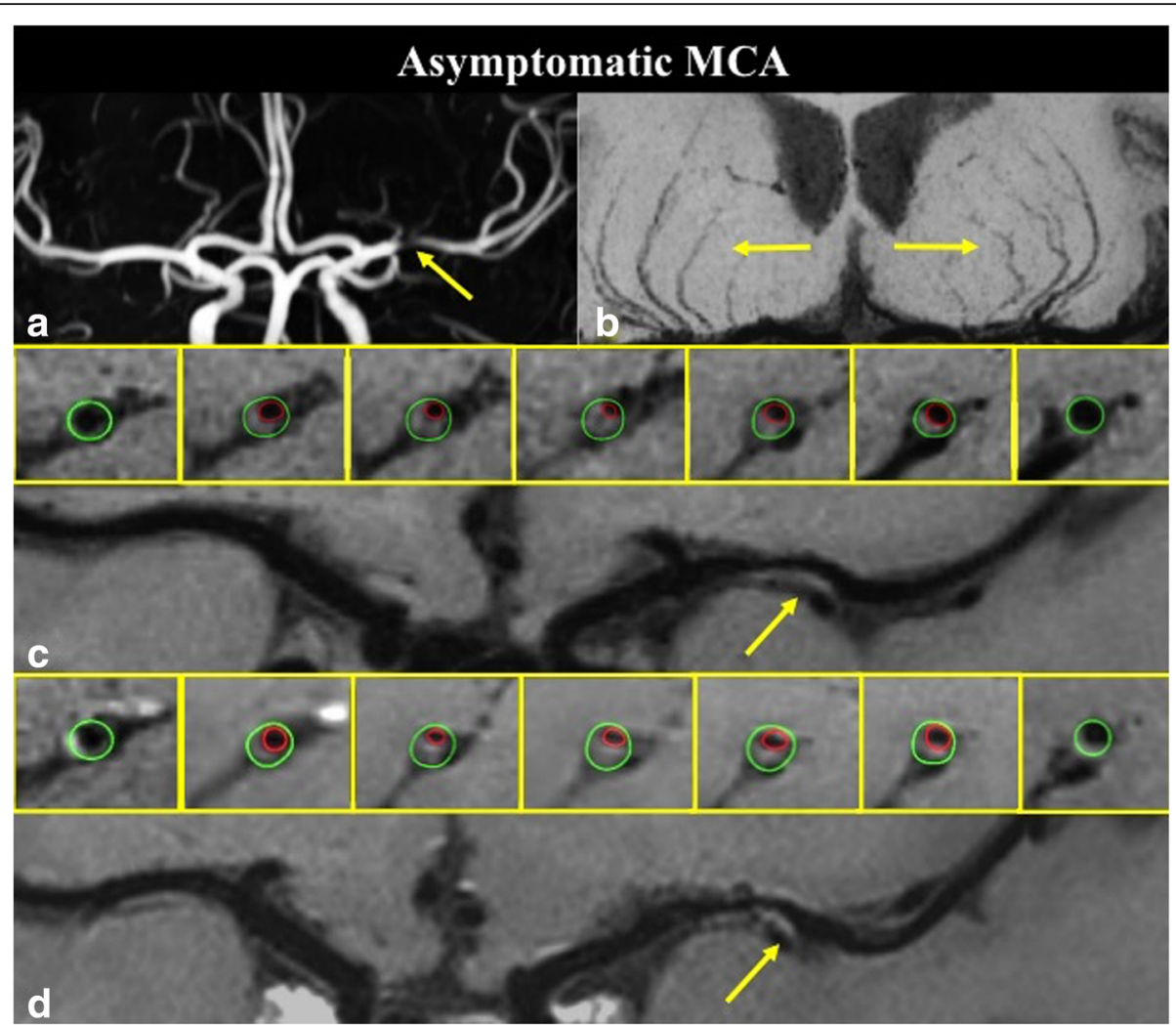

Fig. 4 A 65 years old asymptomatic ICAS patient with severe stenosis on left MCA (a), coronal minimum intensity projection (MinIP) revealed symmetrical LSAs of the left and right hemispheres (b); pre-contrast curved WB-HRCMR and cross-sectional images showed a plaque (c, arrow) on the ventral and inferior side of MCA wall; post-contrast WB-HRCMR showed no enhancement

pre- and post-contrast WB-HRCMR images and contour the enhanced plaque volume, accordingly. Thus, WB-HRCMR enables more accurate measurements of intracranial atherosclerosis plaques characteristics, such as enhancement index and the enhancement volume. We observed that symptomatic MCAs had higher enhancement index and larger enhanced volume of intracranial atherosclerosis plaques.

Recent studies have demonstrated that FSBB-MRA can be used to visualize LSAs [14-16, 27]. Our recent studies proved the feasibility of using whole-brain intracranial vessel wall imaging to depict LSA branches

Table 2 Plaque features and logistic regression analyses in symptomatic and asymptomatic ICAS

\begin{tabular}{|c|c|c|c|c|c|c|c|}
\hline & $\begin{array}{l}\text { Symptomatic ICAS } \\
(N=29)\end{array}$ & $\begin{array}{l}\text { Asymptomatic ICAS } \\
(\mathrm{N}=23)\end{array}$ & $P$ value & $\begin{array}{l}\text { Univariate Analysis } \\
\text { OR(95\%Cl) }\end{array}$ & $P$ value & $\begin{array}{l}\text { Multivariable Analysis } \\
\text { OR(95\%Cl) }\end{array}$ & $P$ value \\
\hline Degree of stenoses (mean $\pm S D, \%)$ & $63.60 \pm 2.80$ & $63.94 \pm 3.02$ & 0.936 & $1.01(0.99-1.04)$ & 0.424 & - & - \\
\hline Remodeling index (mean $\pm S D$, & $0.87 \pm 0.05$ & $0.84 \pm 0.06$ & 0.868 & $1.57(0.18-13.64)$ & 0.681 & - & - \\
\hline Wall area index (mean \pm SD) & $1.35 \pm 0.10$ & $1.26 \pm 0.09$ & 0.517 & $1.46(0.47-4.50)$ & 0.509 & - & - \\
\hline Plaque burden (mean $\pm S D, \%$ ) & $79.39 \pm 1.64$ & $75.71 \pm 2.68$ & 0.227 & 1.03(0.98-1.09) & 0.238 & - & - \\
\hline $\begin{array}{l}\text { Enhancement volume } \\
\left(\text { mean } \pm \mathrm{SD}, \mathrm{mm}^{3}\right)\end{array}$ & $20.70 \pm 3.07$ & $6.71 \pm 1.87$ & 0.001 & $1.02(1.02-1.18)$ & 0.005 & - & - \\
\hline Enhancement index (mean \pm SD) & $0.44 \pm 0.08$ & $0.09 \pm 0.06$ & 0.001 & $23.65(2.63-213.02)$ & 0.005 & $100.43(4.02-2510.96)$ & 0.005 \\
\hline Number of LSA (mean $\pm S D, N)$ & $3.65 \pm 0.18$ & $3.87 \pm 0.21$ & 0.433 & $0.80(0.44-1.41)$ & 0.425 & - & - \\
\hline Total length of LSA (mean \pm SD,mm) & $77.12 \pm 5.16$ & $92.16 \pm 5.15$ & 0.047 & $0.98(0.96-1.00)$ & 0.054 & - & - \\
\hline $\begin{array}{l}\text { Average length of LSA(mean } \pm \\
S D, m m)\end{array}$ & $20.95 \pm 0.87$ & $24.04 \pm 0.95$ & 0.020 & $0.86(0.76-0.98)$ & 0.027 & $0.80(0.65-0.99)$ & 0.036 \\
\hline
\end{tabular}


$[17,18]$. The mean number of LSA branches on normal controls in our study was 4.55, which is consistent with Okuchi's and Kang's previous studies [15, 28]. Compared with normal controls, symptomatic MCAs had a significant decrease in the number and the length of LSAs.

There were several limitations in our study. First, this is an observational study and longitudinal studies are warranted to investigate and expound on the usage of WB-HRCMR in the prediction of stroke outcome and the risk of recurrent stroke. Secondly, the mechanism of plaque enhancement remains unclear and there is no pathological validation of the intracranial plaque vulnerability. Finally, due to the relatively limited spatial resolution used, it is difficult to evaluate the distal small perforating arteries. Partial volume effect of the volume measurement can be overcome by further optimizing imaging parameters or applying with higher field strength.

\section{Conclusions}

WB-HRCMR enabled the comprehensive quantitative evaluation of vessel wall lesions and the LSAs in stroke patients. Symptomatic MCAs have larger enhanced plaque volume, higher enhancement plaque index, and shorter length of LSAs compared with asymptomatic MCAs.

\section{Abbreviations}

CSF: Cerebrospinal fluid; CTA: Computed tomography angiography; DWl: Diffusion weighted imaging; FSBB-MRA: Flow-sensitive black blood magnetic resonance angiography; HDL: High density lipoprotein; HRCMR: High-resolution cardiovascular magnetic resonance imaging; ICAS: Intracranial atherosclerotic stenosis ; IR: Inversion-recovery; LDL: Low density lipoprotein ; LSA: Lenticulostriate artery ; MCA: Middle cerebral artery; MinIP: Minimum intensity projection; MRA: Magnetic resonance angiography; RCVS: Reversible cerebral vasoconstriction syndrome; RI: Remodel index; ROI: Region-of-interest; SI: Signal intensity; SPACE: Sampling Perfection with Application-optimized Contrast using different flip angle Evolutions; TCD: Transcranial Doppler; VA: Vessel area; WA: Wall area; WB-HRCMR: Wholebrain high-resolution cardiovascular magnetic resonance

\section{Acknowledgements}

The authors thank Dr. Haiqing Song, Dr. Qingfeng Ma from Xuanwu Hospital, Capital Medical University for patients recruitment.

\section{Funding}

The study was partially support by National Institutes of Health grant number (5 R01 HL096119-07), National Key R\&D Program of China (2016YFC1301702,2017YFC1307903), Capital Health Research and Development of Special (2016-1-1031),National Science Foundation of China (NSFC 91749127).

\section{Availability of data and materials}

The datasets used and/or analysed during the current study are available from the corresponding author on reasonable request.

\section{Authors' contributions}

Drs QY and XG had full access to all the data in the study and took responsibility for the integrity of the data and the accuracy of the data analysis. Study concept and design: DL, XJ, and QY. Acquisition, analysis, or interpretation of data: MW, HM, YY, ZF, FW. Drafting of the manuscript: MW, QY, XG. Critical revision of the manuscript for important intellectual content: QY. Statistical analysis: HM. Administrative, technical, or material support: DL, XJ. Study supervision: QY, XG. All authors read and approved the final manuscript.

\section{Ethics approval and consent to participate}

All subjects have consented to participate in this study. This research was approved by the Institutional Ethnics Committee for Human Research at Xuanwu Hospital (Beijing, China).

\section{Consent for publication}

All individual person's data has consent for publication obtained from that person.

\section{Competing interests}

The authors declare that they have no competing interests.

\section{Publisher's Note}

Springer Nature remains neutral with regard to jurisdictional claims in published maps and institutional affiliations.

\section{Author details}

${ }^{1}$ Department of Neurology, Xuanwu Hospital, Capital Medical University, Beijing 100053, China. ${ }^{2}$ Department of Radiology, Xuanwu Hospital, Capital Medical University, Beijing 100053, China. ${ }^{3}$ Department of Neurology, Sanbo Brain Hospital, Capital Medical University, Beijing 100093, China. ${ }^{4}$ Biomedical Imaging Research Institute, Cedars Sinai Medical Center, Los Angeles, CA 90048, USA. ${ }^{5}$ Department of Neurosurgery, Xuanwu Hospital, Capital Medical University, Beijing 100053, China.

Received: 4 January 2018 Accepted: 24 May 2018

Published online: 07 June 2018

\section{References}

1. Li H, Wong KS. Racial distribution of intracranial and extracranial atherosclerosis. J Clin Neurosci. 2003;10(1):30-4.

2. $\quad$ Qureshi Al, Caplan LR. Intracranial atherosclerosis. Lancet. 2014;383(9921): 984-98.

3. Feldmann E, Daneault N, Kwan E, Ho KJ, Pessin MS, Langenberg P, Caplan LR. Chinese-white differences in the distribution of occlusive cerebrovascular disease. Neurology. 1990:40(10):1541-5.

4. Wityk RJ, Lehman D, Klag M, Coresh J, Ahn H, Litt B. Race and sex differences in the distribution of cerebral atherosclerosis. Stroke. 1996;27: 1974-80.

5. Kasner SE, Chimowitz MI, Lynn MJ, Howlett-Smith H, Stern BJ, Hertzberg VS, Frankel MR, Levine SR, Chaturvedi S, Benesch CG, et al. Predictors of ischemic stroke in the territory of a symptomatic intracranial arterial stenosis. Circulation. 2006;113(4):555-63.

6. Carvalho M, Oliveira A, Azevedo E, Bastos-Leite AJ. Intracranial arterial stenosis. J Stroke Cerebrovasc Dis. 2014:23(4):599-609.

7. Dubow JS, Salamon E, Greenberg E, Patsalides A. Mechanism of acute ischemic stroke in patients with severe middle cerebral artery atherosclerotic disease. J Stroke Cerebrovasc Dis. 2014;23:1191-4.

8. Sada S, Reddy Y, Rao S, Alladi S, Kaul S. Prevalence of middle cerebral artery stenosis in asymptomatic subjects of more than 40 years age group: a transcranial Doppler study. Neurol India. 2014;62(5):510-5.

9. Mossa-Basha M, Hwang WD, De Havenon A, Hippe D, Balu N, Becker KJ, Tirschwell DT, Hatsukami T, Anzai Y, Yuan C. Multicontrast high-resolution vessel wall magnetic resonance imaging and its value in differentiating intracranial vasculopathic processes. Stroke. 2015;46(6):1567-73.

10. Xu W-H, Li M-L, Gao S, Ni J, Zhou L-X, Yao M, Peng B, Feng F, Jin Z-Y, Cui L-Y. In vivo high-resolution MR imaging of symptomatic and asymptomatic middle cerebral artery atherosclerotic stenosis. Atherosclerosis. 2010;212:507-11.

11. Chen XY, Wong KS, Lam WW, Zhao HL, Ng HK. Middle cerebral artery atherosclerosis: histological comparison between plaques associated with and not associated with infarct in a postmortem study. Cerebrovasc Dis. 2008;25(1-2):74-80.

12. Turan TN, Rumboldt Z, Granholm AC, Columbo L, Welsh CT, Lopes-Virella MF, Spampinato MV, Brown TR. Intracranial atherosclerosis: correlation between in-vivo 3T high resolution MRI and pathology. Atherosclerosis. 2014;237(2):460-3

13. Teng Z, Peng W, Zhan Q, Zhang X, Liu Q, Chen S, Tian X, Chen L, Brown AJ, Graves MJ, et al. An assessment on the incremental value of high-resolution magnetic resonance imaging to identify culprit plaques in atherosclerotic disease of the middle cerebral artery. Eur Radiol. 2016;26(7):2206-14. 
14. Gotoh K, Okada T, Miki Y, Ikedo M, Ninomiya A, Kamae T, Togashi K. Visualization of the lenticulostriate artery with flow-sensitive black-blood acquisition in comparison with time-of-flight MR angiography. J Magn Reson Imaging. 2009:29(1):65-9.

15. Okuchi S, Okada T, Ihara M, Gotoh K, Kido A, Fujimoto K, Yamamoto A, Kanagaki M, Tanaka S, Takahashi R, et al. Visualization of lenticulostriate arteries by flow-sensitive black-blood MR angiography on a 1.5 T MRI system: a comparative study between subjects with and without stroke. AJNR Am J Neuroradiol. 2013;34(4):780-4.

16. Okuchi S, Okada T, Fujimoto K, Fushimi Y, Kido A, Yamamoto A, Kanagaki M, Dodo T, Mehemed TM, Miyazaki M, et al. Visualization of lenticulostriate arteries at 3T: optimization of slice-selective off-resonance sinc pulseprepared TOF-MRA and its comparison with flow-sensitive black-blood MRA. Acad Radiol. 2014;21(6):812-6.

17. Fan Z, Yang Q, Deng Z, Li Y, Bi X, Song S, Li D. Whole-brain intracranial vessel wall imaging at 3 tesla using cerebrospinal fluid-attenuated T1weighted 3D turbo spin echo. Magn Reson Med. 2017;77(3):1142-50.

18. Yang Q, Deng Z, Bi X, Song SS, Schlick KH, Gonzalez NR, Li D, Fan Z. Wholebrain vessel wall MRI: a parameter tune-up solution to improve the scan efficiency of three-dimensional variable flip-angle turbo spin-echo. J Magn Reson Imaging. 2017;46(3):751-7.

19. Marinkovic S, Gibo H, Milisavljevic M, Cetkovic M. Anatomic and clinical correlations of the Lenticulostriate arteries. Clin Anat. 2001;14:190-5.

20. Choi YJ, Jung SC, Lee DH. Vessel Wall imaging of the intracranial and cervical carotid arteries. J Stroke. 2015;17(3):238-55.

21. Skarpathiotakis M, Mandell DM, Swartz RH, Tomlinson G, Mikulis DJ. Intracranial atherosclerotic plaque enhancement in patients with ischemic stroke. AJNR Am J Neuroradiol. 2013;34(2):299-304.

22. Natori T, Sasaki M, Miyoshi M, Ito K, Ohba H, Miyazawa H, Narumi S, Kabasawa H, Harada T, Terayama Y. Intracranial plaque characterization in patients with acute ischemic stroke using pre- and post-contrast threedimensional magnetic resonance Vessel Wall imaging. J Stroke Cerebrovasc Dis. 2016;25(6):1425-30.

23. Ryu CW, Kwak HS, Jahng GH, Lee HN. High-resolution MRI of intracranial atherosclerotic disease. Neurointervention. 2014;9(1):9-20.

24. Vakil P, Vranic J, Hurley MC, Bernstein RA, Korutz AW, Habib A, Shaibani A, Dehkordi FH, Carroll TJ, Ansari SA. T1 gadolinium enhancement of intracranial atherosclerotic plaques associated with symptomatic ischemic presentations. AJNR Am J Neuroradiol. 2013;34(12):2252-8.

25. Qiao Y, Zeiler SR, Mirbagheri S, Leigh R, Urrutia V, Wityk R, Wasserman BA. Intracranial plaque enhancement in patients with cerebrovascular events on high- spatial-resolution MR images. Radiology. 2014;271;271(2):534-42.

26. Kim J-M, Jung K-H, Sohn C-H, Moon J, Shin J-H, Park J, Lee S-H, Han MH, Roh J-K. Intracranial plaque enhancement from high resolution vessel wall magnetic resonance imaging predicts stroke recurrence. Int J Stroke. 2016; 11(2):171-9.

27. Akashi T, Taoka T, Ochi T, Miyasaka T, Wada T, Sakamoto M, Takewa M, Kichikawa K. Branching pattern of lenticulostriate arteries observed by MR angiography at 3.0 T. Jpn J Radiol. 2012;30(4):331-5.

28. Kang CK, Park CA, Park CW, Lee YB, Cho ZH, Kim YB. Lenticulostriate arteries in chronic stroke patients visualised by $7 \mathrm{~T}$ magnetic resonance angiography. Int J Stroke. 2010;5(5):374-80.

\section{Ready to submit your research? Choose BMC and benefit from:}

- fast, convenient online submission

- thorough peer review by experienced researchers in your field

- rapid publication on acceptance

- support for research data, including large and complex data types

- gold Open Access which fosters wider collaboration and increased citations

- maximum visibility for your research: over $100 \mathrm{M}$ website views per year

At BMC, research is always in progress.

Learn more biomedcentral.com/submissions 